\title{
Pre-analytic saliva processing affect proteomic results and biomarker screening of head and neck squamous carcinoma
}

\author{
KAZUFUMI OHSHIRO ${ }^{1}$, DAVID I. ROSENTHAL ${ }^{2}$, JOHN M. KOOMEN ${ }^{3}$, CHARLES F. STRECKFUS ${ }^{4}$, \\ MARK CHAMBERS ${ }^{5}$, RYUJI KOBAYASHI ${ }^{3}$ and ADEL K. EL-NAGGAR ${ }^{1}$ \\ Departments of ${ }^{1}$ Pathology, ${ }^{2}$ Radiation Oncology, ${ }^{3}$ Molecular Pathology, The University of \\ Texas, M.D. Anderson Cancer Center; ${ }^{4}$ Dental Branch, University of Texas, Health Science Center; \\ ${ }^{5}$ Department of Dental Oncology, The University of Texas, M.D. Anderson Cancer Center, Houston, TX, USA
}

Received October 26, 2006; Accepted December 8, 2006

\begin{abstract}
The objective of this study was to assess the effect of pre-analytical processing on proteomic analysis of saliva and to identify salivary biomarkers for potential clinical applications. Saliva samples from five healthy individuals and three head and neck squamous carcinoma (HNSC) patients were initially depleted of major protein constituents. Saliva from healthy subjects was divided and processed by three different methods prior to liquid chromatography and tandem mass spectrometry technique (LC-MS/MS) analysis. The results showed marked differences amongst the methods. The SDS-PAGE separation and in-gel digestion method yielded the highest number of proteins that included the majority of those identified by the other two methods. The in geldigestion method was used in the LC-MS/MS analysis of saliva from three HNSC patients and the results were compared with those from healthy subjects. Our analysis identified two proteins, $\alpha-1$-B-glycoprotein and complement factor B proteins, to be present in patients but not in normal specimens. Paradoxically, cystatin S, parotid secretory factor, and poly4-hydrolase $\beta$-subunit proteins were detected in most normal salivas but not in patient specimens. Subsequent analysis of complement factor B by Western blotting showed strong immunoreactive bands of complement factor B in HNSC patients' and negative or weakly positive in normal saliva samples. We conclude that: 1) initial saliva processing affects
\end{abstract}

Correspondence to: Dr Adel K. El-Naggar, Department of Pathology, University of Texas, M.D. Anderson Cancer Center, 1515 Holcombe Blvd., Unit 085, Houston, TX 77030, USA

E-mail: anaggar@mdanderson.org

Abbreviations: HNSC, head and neck squamous carcinoma; LCMS/MS, liquid chromatography and tandem mass spectrometry; SAX, strong anion exchange; TFA, trifluoroacetic acid; FPLC, fastperformance liquid chromatography; SDS-PAGE, sodium dodecyl sulfate-polyacrylamide gel electrophoresis; PBST, phosphate buffered saline Tween

Key words: saliva, biomarkers, head and neck, squamous cell carcinoma, proteomics protein analysis, 2) in-gel digestion followed by LC-MS/MS detects the most saliva proteins, 3) certain proteins are differentially found in patient and normal salivas and 4) a small set of proteins can be targeted for future validation for clinical investigation.

\section{Introduction}

Saliva is a readily accessible secretion that plays an important role in the maintenance of oral homeostasis, tooth integrity, initiation of digestion, and antimicrobial defense (1-3). Saliva is protein rich and may constitute a valuable source of diagnostic and therapeutic markers in head and neck squamous cell carcinoma (HNSC) patients (4-6). The major components of saliva are mucins, proline-rich glycoproteins, amylase, lipase and a variety of antimicrobial proteins and peptides that include agglutinin, cystatins, lisozyme, lactoferrin, immunoglobulins, histatins and defensins (7-17). Numerous less common proteins derived from either active salivary secretion or through plasma filtration have also been identified (18-21). Analysis of these proteins may provide important information in health and diseased states.

It has recently been acknowledged that proteomic analysis reflects the net sum of the metabolic and functional states of cells and secretions from tissues (22). Advances in both technological and bioinformatic fields have led to a plethora of efforts to identify diagnostic, prognostic and therapeutic targets using human secretions and body fluids (4). However, major obstacles remain to complicate and impede the clinical implementation of this technology in human materials. These include sample-related factors such as quality, timing, composition, sample collection and processing, technical limitations and the complexities and the dynamic variations of human proteins $(22,23)$.

The increasing interest in proteomic profiling of saliva has led to several attempts to characterize its proteins (24-29). In these studies, only a limited number of normal specimens with varied collection and processing methods were analyzed. This suggests the need to define implications of saliva collection and evaluate the role of pre-analytical processing factors on the quality and nature of saliva protein analysis. To address these issues a standardized collection protocol and three different processing techniques were used to prepare 
saliva specimens prior to liquid chromatography-tandem mass spectrometry (LC-MS/MS) analysis. We then used the best method to analyze saliva from HNSC patients and compared the results to those of the healthy subjects to identify biological markers of potential clinical utility.

\section{Materials and methods}

Subjects. Whole saliva specimens were collected according to a standardized protocol from 8 individuals between the hours of 10 a.m. to 4 p.m. who consented to a protocol approved by the M.D. Anderson IRB committee. Of the 8 specimens, 5 were from healthy subjects $(2$ males and 3 females) and 3 from patients with HNSC, 2 males and 1 female. All saliva from HNSC patients were harvested prior to treatment.

\section{Saliva protocol}

Specimen collection. Stimulated whole saliva was collected from healthy volunteers and patients according to the following steps: 1) individuals were abstain from eating, drinking, smoking, or brushing their teeth for at least $60 \mathrm{~min}$ prior to collection, 2) to swallow or discard any accumulated saliva, 3) $\mathrm{x}^{0}$ place a standard piece of paraffin $(1.5 \mathrm{~g})$ in the mouth and chewed on at a regular pace and 4) to expectorate saliva periodically into a preweighed disposable plastic cup with a preservative to inhibit enzymatic activity for a period of $5 \mathrm{~min}$. The cup was then reweighed and the flow rate was determined gravimetrically. The volume and physical characteristics of the specimen were recorded. Whole saliva $(\sim 5 \mathrm{ml})$ was obtained from each individual.

Specimen processing. Each saliva sample was divided into 1-ml aliquots and placed into bar coded cryotubes. The specimens were immediately frozen $\left(-80^{\circ} \mathrm{C}\right)$ until used. Samples were thawed and centrifuged at $14,000 \times \mathrm{g}$ at $4^{\circ} \mathrm{C}$ for $10 \mathrm{~min}$ to remove suspended particulates. A preliminary LC-MS/MS analysis of normal salivas showed that amylase, albumin, immunoglobulins, transferrin and haptoglobin to be the major protein components that may mask the analysis of uncommon and low level proteins. To deplete samples of these proteins we used multiple affinity columns (Agilent, Palo Alto, CA). Saliva supernatant $(200 \mu \mathrm{l})$ was diluted to $450 \mu \mathrm{l}$ with buffer A (Agilent) and subjected to the affinity columns. The volume of saliva used for the depletion process was determined by comparing the level of albumin in serum and saliva using Western blotting with anti-albumin antibody (data not shown). The flow through fractions were collected and dialyzed against water overnight (molecular weight cut-off: $3.5 \mathrm{kDa}$ ). Saliva proteins and peptides $<3.5 \mathrm{kDa}$ were not included in the present study. The samples were then concentrated with vacuum centrifuge and the volume was reconstituted to $50 \mu 1$ with water. Each saliva specimen was divided and analyzed using three different procedures as illustrated in Fig. 1.

\section{Post-depletion processing}

Method 1 (direct analysis). A 5- $\mu 1$ aliquot of depleted saliva was digested overnight with $10 \mu 1$ of $0.5 \mu \mathrm{g} / 50 \mu 1$ modified trypsin (Promega, Madison, WI) in $25 \mathrm{mM}$ ammonium bicarbonate and concentrated by a vacuum centrifuge.

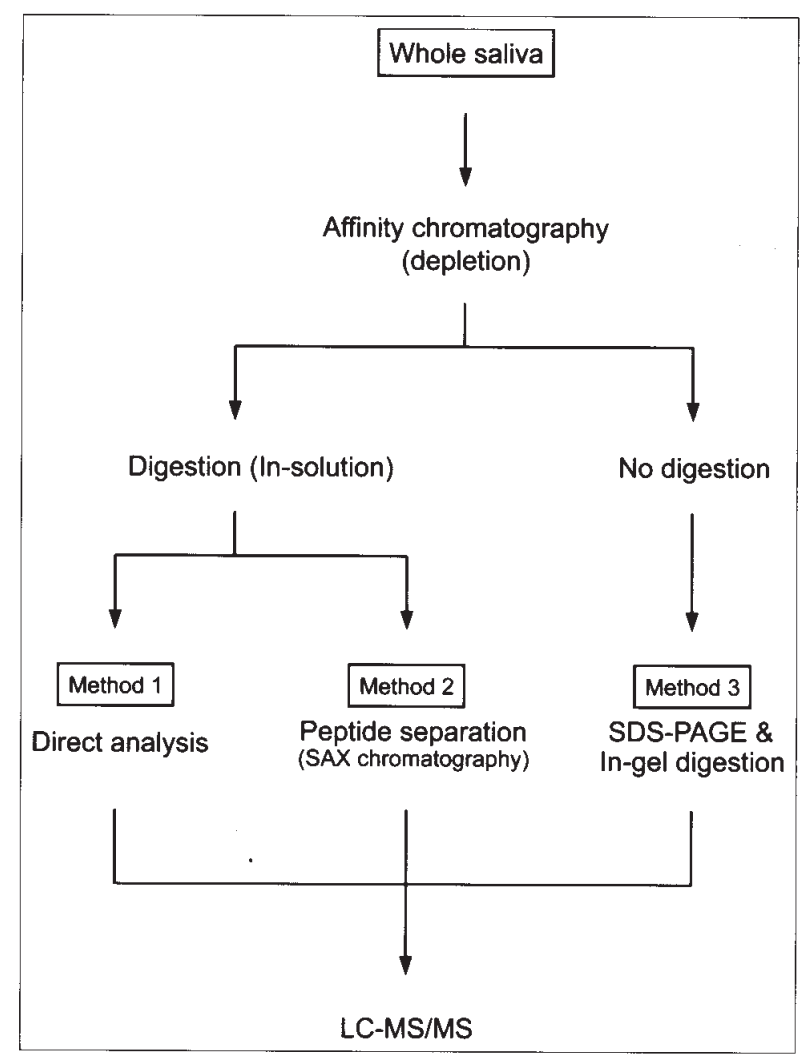

Figure 1. Schematic diagram of saliva protein analysis using three different procedures.

Specimens were reconstituted with $5 \mu 1$ of $5 \mathrm{mM}$ ammonium bicarbonate containing $0.1 \%$ trifluoroacetic acid (TFA) and directly analyzed by LC-MS/MS.

Method 2 [strong anion exchange (SAX) chromatography]. In the second approach, specimens were fractionated using SAX chromatography. A 5- $\mu 1$ aliquot of depleted saliva were digested by trypsin and separated by an FPLC system (BioRad, Hercules, CA) using a SAX column $(5 \times 50 \mathrm{~mm}$, Vydac, Hesperia, CA). The peptides were eluted by a linear gradient of $\mathrm{NaCl}(0-1 \mathrm{M})$. Thirteen elutes were collected and desalted using C-18 96-well solid-phase extraction disk plates (Empore, $3 \mathrm{M}$, St. Paul, MN). Peptides were eluted with aqueous $70 \%$ ACN containing $0.1 \%$ formic acid. The eluted peptide fractions were concentrated with a vacuum centrifuge. Sample volume was reconstituted with $5 \mu \mathrm{l}$ of $5 \mathrm{mM}$ ammonium bicarbonate containing $0.1 \%$ TFA and all fractions of samples were individually analyzed by LC-MS/MS.

Method 3 (sodium dodecyl sulfate-polyacrylamide gel electrophoresis, SDS-PAGE, and in-gel digestion). Saliva proteins were fractionated by SDS-PAGE and subjected to in-gel digestion with trypsin of 11-15 molecular weight zones. Aliquot(s) of saliva samples $(5 \mu 1)$ were prepared previously and separated by a gradient gel [4-15\% Criterion gel (Bio$\mathrm{Rad})]$. After staining of the SDS-PAGE gel with Coomassie brilliant blue, each lane was cut to $11-15$ zones. The proteins in each zone were digested with 100-800 ng of modified trypsin overnight in $25 \mathrm{mM}$ ammonium bicarbonate. The extracted peptides were concentrated and desalted with C18 Ziptips (Millipore) and then analyzed by LC-MS/MS. 
Table I. The numbers of common and uncommon proteins in the saliva among five healthy individuals per each proteomic method.

\begin{tabular}{|c|c|c|c|c|c|c|c|c|c|c|c|c|}
\hline \multirow[b]{2}{*}{ No. } & \multicolumn{4}{|c|}{ Method 1} & \multicolumn{4}{|c|}{ Method 2} & \multicolumn{4}{|c|}{ Method 3} \\
\hline & $\mathrm{U}$ & $\mathrm{C}$ & $\mathrm{M}$ & $\mathrm{T}^{\mathrm{a}}$ & $\mathrm{U}$ & $\mathrm{C}$ & M & $\mathrm{T}^{\mathrm{a}}$ & $\mathrm{U}$ & $\mathrm{C}$ & M & $\mathrm{T}^{\mathrm{a}}$ \\
\hline 1 & 5 & 4 & 35 & 44 & 4 & 11 & 26 & 41 & 6 & 26 & 32 & 64 \\
\hline 2 & 0 & 4 & 10 & 14 & 3 & 11 & 7 & 21 & 11 & 26 & 29 & 66 \\
\hline 3 & 2 & 4 & 8 & 14 & 1 & 11 & 15 & 27 & 6 & 26 & 32 & 64 \\
\hline 4 & 14 & 4 & 26 & 44 & 26 & 11 & 60 & 97 & 27 & 26 & 82 & 135 \\
\hline 5 & 13 & 4 & 25 & 42 & 41 & 11 & 66 & 118 & 56 & 26 & 82 & 164 \\
\hline
\end{tabular}

${ }^{a} \mathrm{U}$, uncommon protein number (these proteins were identified in only one normal saliva specimen); $\mathrm{C}$, common protein number (these proteins were commonly identified in five normal saliva specimens); M, middle group protein number (these proteins were identified in two-four of five normal saliva specimens); $\mathrm{T}$, total protein number.

Liquid chromatography-tandem mass spectrometry (LC-MS/ $M S)$ analysis. Peptides were analyzed by the LC-MS/MS system using an HPLC (LC-packing) with C18 column (Vydac, 0.15x100 mm) to an ion trap (LCQ DecaXP, Thermo, San Jose, CA). The solvent system was $2 \%$ ACN (solvent A) and $60 \% \mathrm{ACN} / 20 \%$ 2-propanol (solvent B); both solvents contained $0.01 \%$ TFA. A linear gradient from 2 to $60 \%$ solvent B over 90 min was used to elute the peptides. Datadependent MS/MS acquisition was performed.

Western blotting. Saliva samples $(5 \mu \mathrm{l})$ prepared as indicated in the Materials and methods were subjected to SDS-PAGE and electroblotted in nitrocellulose membrane, which was preincubated with a blocking buffer (5\% skim milk, phosphate buffered saline Tween (PBST); 0.1\% Tween-20 in PBS) for at least $1 \mathrm{~h}$ at room temperature and incubated with the anticomplement factor B antibody (diluted 1:1000 in blocking buffer, R\&D Systems, Minneapolis, MN) overnight at $4^{\circ} \mathrm{C}$. After washing with PBST, the membrane was incubated with anti-goat IgG antibody conjugated with peroxidase for $1 \mathrm{~h}$ at room temperature. After washing with PBST, areas reacting with the secondary antibody were detected using ECL Western blot detection reagents (Amersham Pharmacia) and X-ray film.

Database search. The MS/MS data obtained by method 1 were searched using MASCOT (Matrix Science, Boston, MA) against human entries in the NCBI (National Center for Biotechnology Information) database, selecting methionine oxidation as a variable modification and trypsin specificity. The $\mathrm{m} / \mathrm{z}$ tolerance settings were \pm 2.0 for parent ions and \pm 0.8 for fragment ions. Data files were created from all the MS/MS data obtained by methods 2 and 3 using Bioworks Browser and merged to one file, respectively. MASCOT searching was done for each merged file using the same database, modification and parameters to those listed above. All MASCOT searching results were manually verified for their reliability.

\section{Results}

Proteins identified in all specimens and proteins unique to individual specimens (uncommon proteins) varied within samples and methods. The number of proteins found in all 5 normal specimens by each method were 4 by method 1,11 by method 2 , and 26 by method 3 . A list of saliva proteins from healthy normal specimens are presented in Table I.

Proteins in individual samples identified by each method are listed in Table II. Four proteins, $\alpha$-amylase, bactericidal/ permeability-increasing protein-like 1 , chromosome 6 open reading frame 58, and hypothetical protein L00124220 were identified by all 3 methods. Method 2 identified cystatin SN precursor and prolyl 4-hydroxylase, $\beta$ subunit that was not identified by method 3 . Method 3 identified 12 additional proteins that included $\beta$-actin, carbonic anhydrase VI, cystatins, $\alpha$ enolase, heat shock $70-\mathrm{kDa}$ protein $1 \mathrm{~A}$, kallikrein, S100 calcium binding protein A9, serine (or cysteine) proteinase inhibitor, clade B, member 1 , thioredoxin, transcobolamin I precursor and an unnamed protein product.

Saliva analysis of cancer patients identified 34 proteins to be consistently present in all samples (Tables III and IV). Of these, $\alpha-1-B$-glycoprotein and complement factor B were not identified in any saliva samples from the healthy individuals. Also, $\alpha$-1-acid glycoprotein 2 precursor (gil29170378), fibronectin 1 (gil53791223) and kininogen (gil386853) were identified in 2 of the 3 cancer specimens, but not in the saliva of the healthy individuals (data not shown). $\alpha$-fibrinogen precursor, annexin I, ceruloplasmin, fibrinogen- $\gamma$, hemopexin, keratin 1, keratin 10, matrix metalloproteinase 9, and proapolipoprotein were found in all cancer samples and were only present in the saliva from 1 or 2 of the 5 healthy subjects (Table IV). We also identified cystatin $\mathrm{S}$ and parotid secretory proteins to be present in normal specimens but not in saliva of the cancer patients.

To validate the LC-MS/MS analysis of complement factor B, Western blotting was performed on the saliva from the 5 healthy individuals and 9 cancer subjects including the 3 original cancer patient specimens. Western blot analysis of salivary complement factor B revealed low levels of protein in salivas from healthy subjects. In contrast, higher band intensities were found in specimens from cancer subjects. Fig. 2 shows multiple immunoreactive bands of variable intensities of complement factor B and only one HNSC sample (Patient lane 4) was negative. Western blot analysis identified complement factor B in all three original HNSC salivas (Patient lanes 1,2 and 9). 
Table II. Saliva proteins identified in all five healthy specimens by each processing method.

\begin{tabular}{lllll}
\hline & & \multicolumn{3}{c}{ Number of proteins } \\
\cline { 2 - 4 } Protein designation & Accession no. & Method 1 & Method 2 & Method 3 \\
\hline -amylase & gil1785855 & 5 & 5 & 5 \\
$\alpha$-enolase & gil2661039 & 2 & 4 & 5 \\
B-actin & gil4501885 & 3 & 4 & 5 \\
Bactericidal/permeability-increasing protein-like 1 & gil15055535 & 5 & 5 & 5 \\
Carbonic anhydrase VI & gil14530767 & 3 & 4 & 5 \\
Chromosome 6 open reading frame 58 & gil55665009 & 5 & 5 & 5 \\
Cystatin A & gil6503217 & 0 & 3 & 5 \\
Cystatin B & gil30582919 & 2 & 3 & 5 \\
Cystatin C & gil181387 & 0 & 4 & 5 \\
Cystatin D & gil398711 & 2 & 3 & 5 \\
Cystatin S & gil30366 & 4 & 3 & 5 \\
Cystatin SA & gil359513 & 1 & 2 & 5 \\
Cystatin SN precursor & gil118188 & 1 & 5 & 3 \\
DMBT1 & gil4996278 & 4 & 5 & 5 \\
Heat shock 70-kDa protein 1A & gil62089222 & 1 & 2 & 5 \\
Hypothetical protein L00124220 & gil21687060 & 5 & 5 & 5 \\
Kallikrein 1 & gil20160213 & 3 & 4 & 5 \\
Lactotransferrin & gil18490850 & 2 & 5 & 5 \\
Lysozyme C precursor & gil48428995 & 4 & 5 & 5 \\
Mucin 5B precursor & gil23821885 & 3 & 5 & 5 \\
Neutrophil gelatinase-associated lipocalin & gil300181 & 3 & 5 & 5 \\
Parotid secretory protein & gil16755850 & 1 & 3 & 5 \\
Prolyl 4-hydroxylase, B subunit & gil48735337 & 2 & 5 & 4 \\
S100 calcium binding protein A9 & gil4506773 & 3 & 3 & 5 \\
Serine (or cysteine) proteinase inhibitor, clade B, member 1 & gil30582695 & 0 & 2 & 5 \\
Thioredoxin & gil9508997 & 0 & 4 & 5 \\
Transcobalamin I precursor & gil135533 & 0 & 1 & 5 \\
Unnamed protein product & gil34527805 & 0 & 3 & 5 \\
\hline & & & \\
\hline
\end{tabular}

Table III. Categories of saliva proteins in patients with HNSC specimens using method 3 .

\begin{tabular}{lllll}
\hline Subjects & U & C & M & T $^{\mathrm{a}}$ \\
\hline HNSC no. 1 & 33 & 34 & 29 & 96 \\
HNSC no. 2 & 14 & 34 & 29 & 77 \\
HNSC no. 3 & 33 & 34 & 29 & 96 \\
\hline
\end{tabular}

${ }^{\mathrm{a}} \mathrm{U}$, uncommon (proteins identified in saliva of only one HNSC subject); C, common (proteins identified in all specimens from HNSC subjects); $M$, intermediate (proteins identified in 2 of 3 HNSC subjects); T, total proteins.

Complement factor B (93 kDa) possesses non-glycosylated and glycosylated forms (30-32), and is cleaved by factor D into $\mathrm{N}$-terminal Ba fragment $(30 \mathrm{kDa})$ and $\mathrm{C}$-terminal $\mathrm{Bb}$ fragments (63 kDa) (33). Low and high molecular weight bands of complement factor B in Patient lanes 1, 2, and 9 in Fig. 2 represent $\mathrm{Bb}$ fragment and intact complement factor $\mathrm{B}$ by
LC-MS/MS analysis (method 3) of gel bands and corresponds to $\sim 55-75 \mathrm{kDa}$ and $75-100 \mathrm{kDa}$, respectively. Therefore, large and small bands indicated by arrows in lanes 1, 5, 6, 7, 8 and 9 and normal lane 4 may represent non-glycosylated forms of total complement factor $\mathrm{B}$ and its $\mathrm{Bb}$ fragment and large and small bands indicated by arrowheads (Patient lanes 2, 3, and 6 and normal lane 5) the corresponding glycosylated forms.

\section{Discussion}

Saliva is a complex secretion affected by numerous intrinsic and external factors that influence the rate, content and quality of secreted materials. Therefore, efforts to minimize the effect of these factors and to develop a simplified and standardized practical procedure for saliva analysis are required. We employed a standardized protocol for stimulated whole saliva collection to reduce variability. Although the protocol is not as selective as individual glandular sampling, it is practical for harvesting whole saliva with minimal circadian fluctuations effect. It also provides a copious quantity in convenient and simplified steps for the patients. 
Table IV. Individual saliva proteins commonly present in all HNSC specimens and their frequency in normal specimens.

Protein designation

Aldolase A

$\alpha$-2-macroglobulin

$\alpha-1-B-$ glycoprotein

$\alpha$-enolase

$\alpha$-fibrinogen precursor

Annexin I

B-actin

Ceruloplasmin

Complement component 3

Complement factor B

Cystatin B

Fibrinogen- $\gamma$

Gelsolin isoform b

Glucose phosphate isomerase

Heat shock $70-\mathrm{kDa}$ protein $1 \mathrm{~A}$

Heat shock $70-\mathrm{kDa}$ protein 8 isoform 1

Hemopexin

Keratin 1

Keratin 10

Lactotransferrin

Lipocalin 1

Matrix metalloproteinase 9

Mucin 5B precursor

Myeloperoxidase precursor (MPO)

Neutrophil gelatinase-associated lipocalin

Peptidylprolyl isomerase A, isoform 1

Phosphogluconate dehydrogenase

Proapolipoprotein

S100 calcium binding protein A8

S100 calcium binding protein A9

Serine (or cysteine) proteinase inhibitor, clade B, member 1

Thioredoxin

Transaldolase 1

Transcobalamin I precursor
Accession no

Number of positive specimens in healthy salivas

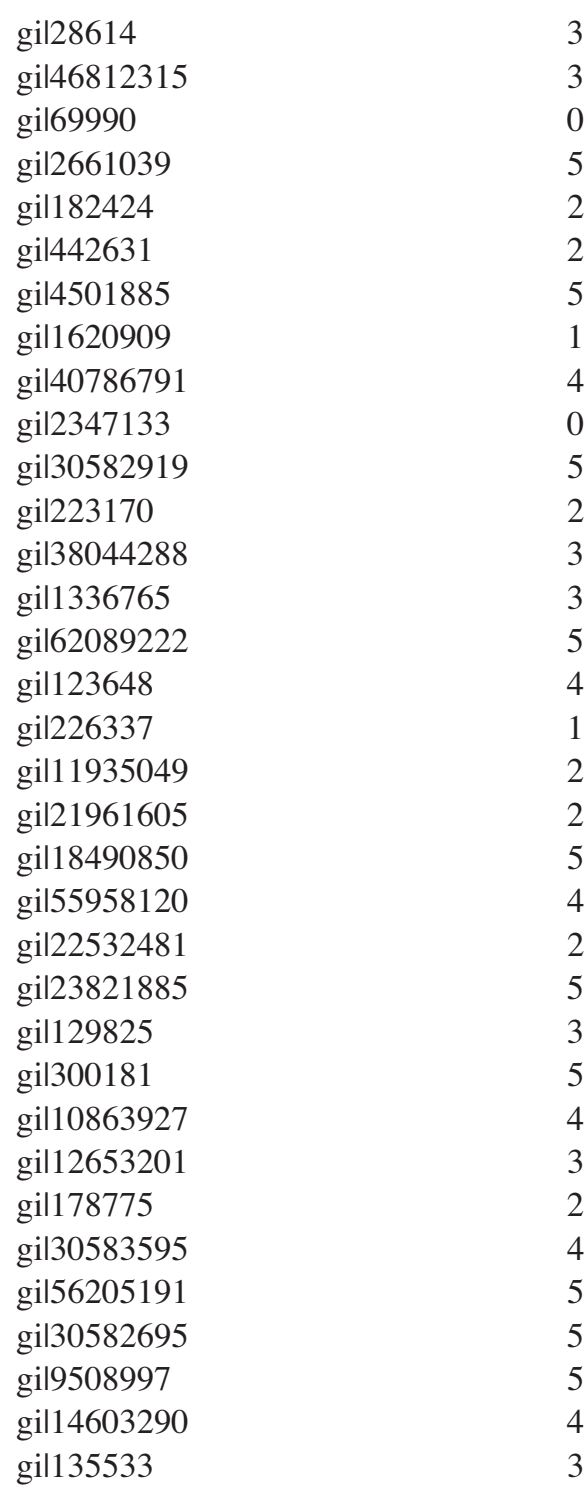

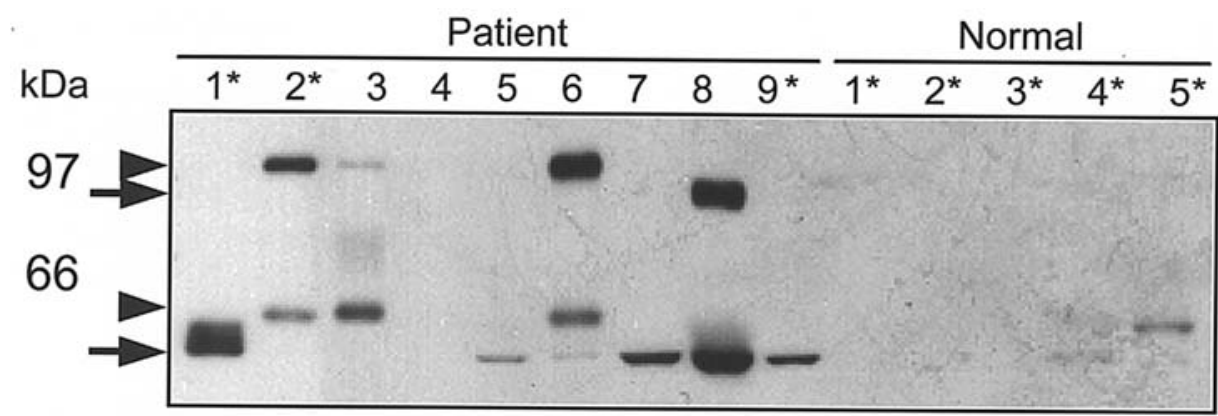

Figure 2. Western blotting of complement factor B in the saliva from normal individuals and head and neck squamous carcinoma subjects. Depleted saliva samples $(5 \mu \mathrm{l})$ were loaded to a polyacrylamide gel $(8 \%)$, electroblotted, and probed with anti-complement factor B antibody. Asterisks indicate the saliva samples analyzed by LC-MS/MS. Complement factor B (93 kDa) is cleaved by factor D into N-terminal Ba fragment (30 kDa) and C-terminal Bb fragments (63 kDa) (33) and possesses non-glycosylated and glycosylated forms (30-32). Therefore, two bands indicated by arrows (patient lanes 1, 5, 6, 7, 8 and 9 and normal lane 4) are non-glycosylated forms of intact complement factor B and Bb fragment, respectively, while two bands indicated by arrowheads (patient lanes 2, 3 and 6 and normal lane 5) are glycosylated forms of intact complement factor B and Bb fragment, respectively. 
Our analysis of salivas by three different processing methods identified a set of shared and distinctive proteins among samples from healthy individuals. SDS-PAGE and ingel digestion yielded the highest number of proteins which included the majority of proteins identified by the other two methods. However, the SAX chromatography processing method identified several unique proteins that were not detected by the other two methods. Our data suggest(s) that multiple processing methods may be needed to account for the wide range of saliva proteins. Our results also show that only four saliva proteins were common in all specimens by the three methods. A previous saliva study using a two-dimensional (2D)-LC technique reported 102 proteins in their sample (28). The same method in our study yielded 118 saliva proteins. In contrast, $\mathrm{Hu}$ et al (25) and Xie et al (29) reported 309 and 437 uncommon proteins using molecular weight fractionation and peptide separation by free flow electrophoresis and LCMS/MS, respectively. Interestingly, 15 and 27 of the proteins reported in these studies were among the 28 proteins found in all of our normal specimens $(25,29)$.

Our results of salivas from cancer patients identified 34 proteins to be present in all three specimens. The majority of these proteins were also found in normal salivas processed by the method except the $\alpha-1-B-$ glycoprotein and complement factor $B$. None of these proteins have previously been reported in other studies of normal saliva (24-26,28,29). However, our Western blotting detected low levels of complement factor B in saliva of 2 of the 5 normal salivas. This finding can be attributed to differences in the sensitivity between these methods and underscore the importance of validating proteomic analysis using established and standardized techniques. Similar validation of the $\alpha-1-B-$ glycoprotein by Western analysis was precluded by the lack of antibody specific for this marker.

Complement factor B is a component of the alternative complement pathway and its expression is considered to be restricted to hepatocytes, monocytes, and fibroblasts (34). This factor has been reported to be elevated in several tumors and thought to be induced by cytokines including interleukins and interferons (30-32,35,36-38). Complement factor B $(93 \mathrm{kDa})$ is cleaved by factor D into N-terminal $\mathrm{Ba}(30 \mathrm{kDa})$ and C-terminal $\mathrm{Bb}(63 \mathrm{kDa})$ fragments (33). The latter fragment was found to induce apoptosis, most likely through the effect on host immune response by complement factor Bderived fragment $\mathrm{Bb}$ in leukemia studies (39). Support for such immune-mediated effects are reported by Andoh et al where complement factor B has been identified in the saliva of healthy individuals by immunoblotting (40). $\alpha$-1-B-glycoprotein is a member of the immunoglobulin super family and is a constant component of serum (41). Although no biological function of $\alpha-1-B-$ glycoprotein is known, it has been shown recently to form a complex with cysteine-rich secretory protein-3 that may play a possible role in the innate immune system (42).

We also identified $\alpha$-1-acid glycoprotein 2 precursor, fibronectin 1 and kininogen proteins in saliva from 2 of the 3 HNSC patients, but not in saliva of the healthy individuals. Similarly, two proteins identified in our normal saliva specimens (cystatin $\mathrm{S}$ and parotid secretory protein) were not found in any of the saliva samples from HNSC patients. Both proteins have also been identified in previous studies of normal saliva proteins $(25,27-29)$. These and other proteins can be targeted for future validation as potential markers in clinical setting. Moreover, further efforts should be directed to unravel the functional role and regulation of these proteins in HNSC tumorigenesis. This information is necessary to determine the ultimate diagnostic, prognostic and therapeutic values of these proteins.

Our data showed that: 1) collection and processing of saliva plays a major role in proteomic analysis, 2) saliva is a convenient source of unique protein biomarkers of potential clinical value and 3) certain saliva proteins are differentially identified between HNSC patients and healthy individuals.

\section{Acknowledgments}

This work was supported in part by the Kenneth D. Müller Professorship and a National Cancer Institute Specialized Program of Research Excellence grant in Head and Neck Cancer (SPORE).

\section{References}

1. Humphrey SP and Williamson RT: A review of saliva: normal composition, flow, and function. J Prosthet Dent 85: 162-169, 2001 .

2. Amerongen AV and Veerman EC: Saliva - the defender of the oral cavity. Oral Dis 8: 12-22, 2002.

3. Van Nieuw AA, Bolscher JG and Veerman EC: Salivary proteins: protective and diagnostic value in cariology? Caries Res 38: 247-253, 2004.

4. Drake RR, Cazare LH, Semmes OJ and Wadsworth JT: Serum, salivary and tissue proteomics for discovery of biomarkers for head and cancers. Expert Rev Mol Diagn 5: 93-100, 2005.

5. El-Naggar AK, Mao L, Staerkel G, Coombes MM, Tucker SL, Luna MA, Clayman GL, Lippman S and Goepfert H: Genetic heterogeneity in saliva from patients with oral squamous carcinomas: implications in molecular diagnosis and screening. J Mol Diagn 3: 164-170, 2001.

6. Kaufman E and Lamster IB: Analysis of saliva for periodontal diagnosis - a review. J Clin Periodontol 27: 453-465, 2000.

7. Bellamy W, Takase M, Yamauchi K, Wakabayashi H, Kawase K and Tomita M: Identification of the bactericidal domain of lactoferrin. Biochim Biophys Acta 112: 130-136, 1992.

8. Blankenvoorde MF, van't Hof W, Walgreen-Weterings E, van Steenbergen TJ, Brand HS, Nieuw Amerongen AV and Veerman EC: Cystatin and cystatin-derived peptides have antibacterial activity against the pathogen Porphyromonas gingivalis. Biol Chem 379: 1371-1375, 1998.

9. Dale BA and Krisanaprakornkit S: Defensin antimicrobial peptides in the oral cavity. J Oral Pathol Med 30: 321-327, 2001.

10. Dowd FJ: Saliva and dental caries. Dent Clin North Am 43: 457-597, 1999.

11. Ericson $\mathrm{T}$ and Rundegren $\mathrm{J}$ : Characterization of a salivary agglutinin reacting with a serotype c strain of Streptococcus mutans. Eur J Biochem 133: 255-261, 1983.

12. Henskens YM, Veerman EC and Nieuw Amerongen AV: Cystatins in health and disease. Biol Chem Hoppe Seyler 377: 71-86, 1996.

13. Lamont RJ, Demuth DR, Davis CA, Malamud D and Rosan B: Salivary-agglutinin-mediated adherence of Streptococcus mutans to early plaque bacteria. Infect Immun 59: 3446-3450, 1991.

14. Mackay BJ, Denepitiya L, Iacona VJ, Krost SB and Pollock JJ: Growth-inhibitory and bactericidal effects of human parotid salivary histidine-rich polypeptides on Streptococcus mutans. Infect Immun 44: 695-701, 1984.

15. Mathews M, Jia HP, Guthmiller JM, Losh G, Graham S, Johnson GK, Tack BF and McCray PB Jr: Production of betadefensin antimicrobial peptides by the oral mucosa and salivary gland. Infect Immun 67: 2740-2745,1999.

16. McNabb PC and Tomasi TB: Host defense mechanisms at mucosal surfaces. Annu Rev Microbiol 35: 477-496, 1981. 
17. Oppenheim FG, Xu T, McMilliam FM, Levitz SM, Diamond RD, Offner GD and Troxler RF: Histatins, a novel family of histidine-rich proteins in human parotid secretion. Isolation, characterization, primary structure, and fungistatic effects on Candida albicans. J Biol Chem 263: 7472-7477, 1988.

18. Pollock JJ, Lotardo S, Gavai R and Grossbard BL: Lysozymeprotease-inorganic monovalent anion lysis of oral bacterial strains in buffers and stimulated whole saliva. J Dent Res 66: 467-474, 1987.

19. Slomiany BL, Murty VL, Piotrowski J and Slomiany A: Salivary mucins in oral mucosal defense. Gen Pharmacol 27: 761-771, 1996.

20. Tabak LA: Structure and function of human salivary mucins. Crit Rev Oral Biol Med 1: 229-234, 1990.

21. Tenovuo J, Lumikari M and Soukka T: Salivary lysozyme, lactoferrin and peroxidases: antibacterial effects on cariogenic bacteria and clinical applications in preventive dentistry. Proc Finn Dent Soc 87: 197-208, 1991.

22. Caprioli RM: Deciphering protein molecular signatures in cancer tissues to aid in diagnosis, prognosis, and therapy. Cancer Res 65: 10642-10645, 2005.

23. Yarbrough WG, Slebos RJC and Liebler D: Proteomics: clinical applications for head and neck squamous cell carcinoma. Head Neck 26: 549-558, 2006.

24. Hardt M, Thomas LR, Dixon SE, Newport G, Agabian N, Prakobphol A, Hall SC, Witkowska HE and Fisher SJ: Toward defining the human parotid gland salivary proteome and peptidome: Identification and characterization using 2D SDS-PAGE, ultrafiltration, HPLC, and mass spectrometry. Biochemistry 44: 2885-2899, 2005.

25. Hu S, Xie Y, Ramachandran P, Ogorzalek Loo RR, Li Y, Loo JA and Wong DT: Large-scale identification of proteins in human salivary proteome by liquid chromatography/mass spectrometry and two-dimensional gel electrophoresis-mass spectrometry. Proteomics 5: 1714-1728, 2005

26. Huang CM: Comparative proteomic analysis of human whole saliva. Arch Oral Biol 49: 951-962, 2004.

27. Vitorino R, Lobo MJ, Ferrer-Correira AJ, Dubin JR, Tomer KB, Domingues PM and Amado FM: Identification of human whole saliva protein components using proteomics. Proteomics 4: 1109-1115, 2004

28. Wilmarth PA, Riviere MA, Rustvold DL, Lauten JD, Madden TE and David LL: Two-demensional liquid chromatography study of the human whole saliva proteome. J Proteome Res 3: 1017-1023, 2004

29. Xie H, Rhodus NL, Griffin RJ, Carlis JV and Griffin TJ: A catalogue of human saliva proteins identified by free flow electrophoresis-based peptide separation and tandem mass spectrometry. Mol Cell Proteomics 4: 1826-1830, 2005.

30. Andoh A, Fujiyama Y, Bamba T and Hosoda S: Differential cytokine regulation of complement $\mathrm{C} 3, \mathrm{C} 4$, and factor B synthesis in human intestinal epithelial cell line, Caco-2. J Immunol 151: 4239-4247, 1993.
31. Morris KM, Aden DP, Knowles BB and Colten HR: Complement biosynthesis by the human hepatoma-derived cell line HepG2. J Clin Invest 70: 906-913, 1982.

32. Yancey KB, Overholser O, Domloge-Hultsch N, Li LJ, Caughman SW and Bisalbutra P: Human keratinocytes and A-431 cells synthesize and secrete factor B, the major zymogen protease of the alternative complement pathway. J Invest Dermatol 98: 379-383, 1992.

33. Kolb WP, Morrow PR and Tamerius JD: Ba and Bb fragments of factor B activation: fragment production, biological activities, neoepitope expression and quantitation in clinical samples. Complement Inflamm 6: 175-204, 1989.

34. Perlmutter DH and Colten HR: Molecular immunobiology of complement biosynthesis: a model of single-cell control of effector-inhibitor balance. Annu Rev Immunol 4: 231-251, 1986.

35. Watanable I, Horiuchi T and Fujita S: Role of protein kinase C activation in synthesis of complement components $\mathrm{C} 2$ and factor B in interferon-gamma-stimulated human fibroblasts, glioblastoma cell line A172 and monocytes. Biochem J 305: 425-431, 1995.

36. Barnum SR, Ishii Y, Agrawal A and Volanakis JE: Production and interferon-gamma-mediated regulation of complement component $\mathrm{C} 2$ and factors $\mathrm{B}$ and $\mathrm{D}$ by the astroglioma cell line U105-MG. Biochem J 287: 595-601, 1992.

37. Falus A, Rokita H, Walcz E, Brozik M, Hidvegi T and Meretey K: Hormonal regulation of complement biosynthesis in human cell lines-II. Upregulation of the biosynthesis of complement components $\mathrm{C} 3$, factor $\mathrm{B}$ and $\mathrm{C} 1$ inhibitor by interleukin- 6 and interleukin-1 in human hepatoma cell line. Mol Immunol 27: 197-201, 1990.

38. Doustjalai SR, Yusof R, Yip CH, Looi LM, Pillay B and Hashim OH: Aberrant expression of acute-phase reactant proteins in sera and breast lesions of patients with malignant and benign breast tumors. Electrophoresis 25: 2392-2401, 2004.

39. Uwai M, Terui Y, Mishima Y, Tomizuka H, Ikeda M, Itoh T, Mori M, Ueda M, Inoue R, Yamada M, Hayasawa $H$, Horiuchi $T$, Niho Y, Matsumoto M, Ishizaka Y, Ikeda K, Ozawa K and Hatake K: A new apoptotic pathway for the complement factor B-derived fragment Bb. J Cell Physiol 195: 280-292, 2000.

40. Andoh A, Fujiyama Y, Kumra T, Uchihara H, Sakumoto H, Okabe $\mathrm{H}$ and Bamba T: Molecular characterization of complement components $(\mathrm{C} 3, \mathrm{C} 4$, and factor B) in human saliva. J Clin Immunol 17: 404-407, 1997.

41. Juneja RK, Saha N, Tay JS, Low PS and Gahne B: Distribution of plasma alpha-1-B-glycoprotein (A1BG) polymorphism in several populations of the Indian subcontinent. Ann Hum Biol 21: 443-448, 1994.

42. Udby L, Sorensen OE, Pass J, Johnsen AH, Behrendt N, Borregaard $\mathrm{N}$ and Kjeldsen L: Cysteine-rich secretory protein 2 is a ligand of alpha-1-B-glycoprotein human plams. Biochemistry 43: $12877-12886,2004$. 